\title{
Avaliação em larga escala, currículo e diversidade cultural
}

Marinete da Frota Figueredo ${ }^{1}$ Dinalva de Jesus Santana Macêdo² Sônia Maria Alves de Oliveira Reis ${ }^{3}$

\section{Considerações iniciais}

Ao longo dos anos, as avaliações em larga escala vêm assumindo posição de destaque no cenário educacional brasileiro e, gradualmente, vinculadas ao discurso e às articulações voltadas à melhoria da educação, passaram a integrar-se ativamente às políticas e às práticas governamentais direcionadas à Educação Básica e ao Ensino Superior.

Compreendidas como parâmetro de qualidade da educação, as avaliações em larga escala ganham sustentação junto às políticas públicas e ao currículo escolar (SOUZA; ARCAS, 2010), deslocando suas prioridades e revelando-se incoerentes à Constituição Federal de 1988, que assegura a educação como um direito de todos/as, assim como às memórias, às culturas e aos movimentos múltiplos que tecem a sociedade brasileira e retratam o ambiente escolar.

Não desconsideramos o potencial da avaliação. Avaliar é um subsídio de um acompanhamento necessário à produção do conhecimento, que possibilita investigar, mediar, provocar, no sentido de construir caminhos acessíveis e qualitativos à construção do conhecimento. Assim, defendemos uma avaliação que tenha como objetivo observar permanentemente o processo de ensino e de aprendizagem, vislumbrando uma ação educativa que possibilite o percurso individual dos/as estudantes (HOFFMANN, 2001).

Todavia, atentamo-nos para os movimentos das avaliações em larga escala no Brasil e para os seus reflexos nas escolas deste país, que ainda é asfixiado por desigualdades, caracterizado pela negação de direitos e pela exclusão da diversidade cultural. De acordo com Ivo e Hypolito (2017), a educação tem sido modificada de forma muito abrangente em direção

\footnotetext{
${ }^{1}$ Faculdade de Educação da Universidade de São Paulo (FE/USP), São Paulo. marinetefrota@hotmail.com.

2 Universidade do Estado da Bahia (UNEB), Guanambi/BA. dinalvamacedo@hotmail.com.

${ }^{3}$ Universidade do Estado da Bahia (UNEB), Guanambi/BA. sonia_uneb@hotmail.com.
} 
ao atendimento do mercado de trabalho, baseando-se em metas, resultados e avaliação, especialmente, nas avaliações em larga escala, que são associadas a outros mecanismos de controle. Nesse sentido, concordamos com Freitas (2013) ao afirmar que os testes têm o seu lugar na educação como ferramentas de pesquisa, entretanto, o grave problema é que eles foram capturados pelo mercado como mecanismo de controle ideológico dos objetivos da educação e, também, dos/as envolvidos/as no processo educativo. Com essa intenção, de acordo com o autor, as limitações das avaliações em larga escala são ignoradas e a meritocracia e a responsabilização, que são os princípios fundamentais do mercado, ganham centralidade nos projetos educacionais.

Tendo esse quadro como pano de fundo, propomos discutir acerca das avalições em larga escala e as suas implicações para o currículo escolar e para a diversidade cultural. À vista disso, é pertinente frisar que entendemos o currículo como um artefato cultural constituído por relações de poder, o qual produz e induz saberes e que forja identidades (SILVA, 2011). Ademais, compreendemos diversidade cultural como uma construção que se dá lado a lado aos processos identitários e está vinculada aos movimentos históricos, econômicos, políticos e culturais (GOMES, 2007).

Com essa compreensão, as linhas deste texto são tecidas mediante a defesa de escolas onde todos/as sejam vistos/as como sujeitos de direitos e perante inquietações inerentes à condição da diversidade cultural no currículo escolar. Vale dizer, portanto, que "[...] assumir a diversidade é posicionar-se contra as diversas formas de dominação, exclusão e discriminação. É entender a educação como um direito social e o respeito à diversidade no interior de um campo político" (GOMES, 2007, p.41).

Assim sendo, o texto visa a contribuir com o debate a respeito dos arranjos mercadológicos e excludentes que atravessam o sistema educacional brasileiro e, também, agregar forças em prol de uma educação equitativa. Com essa intenção, foi organizado em duas partes somadas às considerações finais. Na primeira delas, abordamos a respeito das avalições em larga escala e as implicações para o currículo; na segunda, discutimos a diversidade cultural no contexto dessas avaliações. E, nas considerações finais, apresentamos uma síntese interpretativa das principais reflexões tecidas quanto ao objetivo deste texto. 


\section{As avaliações em larga escala e as implicações para o currículo escolar}

A partir da segunda metade da década de 1990, do século passado, a educação brasileira vem passando por transformações e reformas estruturais, a fim de moldar o Estado Brasileiro às políticas e aos órgãos financeiros internacionais. Tal processo fundamenta-se em projetos mercadológicos, na redução de gastos, na produtividade e em privatizações, isto é, na redução da atuação do Estado (CÁRIA; OLIVEIRA, 2015). Assim, a política dos resultados passa a orientar a gestão pública e o sistema educacional, viabilizando as avaliações em larga escala, que assumem o papel de medir a "qualidade" da educação, sendo, pretensiosamente, um instrumento de prestação de contas e de ajuste do sistema educacional às regulações do Estado.

Esse movimento é articulado por meio de um discurso voltado para a criação de uma noção de que as reformas são necessárias, em atendimento às demandas da globalização, do mercado internacional e de uma economia baseada no conhecimento com perspectiva mercadológica. Cenário que conduz as políticas educacionais e curriculares a um deslocamento da esfera do político para a esfera do econômico (HYPÓLITO, 2010).

Dessa maneira, segundo Louzada e Marques (2015), a escola passa a ser comparada a uma empresa, e a educação é vista como um produto mercadológico, sendo avaliada por mecanismos de controle, eficiência e operacionalidade do ensino. As avaliações em larga escala são convertidas em uma ferramenta de pressão, de mapeamento, de domínio e de responsabilização dos sujeitos e passam a configurar-se em um elemento chave da qualidade, do sucesso ou do insucesso da educação. Qualidade, por essa ótica, é "traduzida como

desempenho, resultado mensurável e aparentemente 'neutro', 'apolítico', universal e padronizado" (LOUZADA; MARQUES, 2015, p.19).

Por esse prisma, ao longo dos anos, as avaliações em larga escala tornaram-se instrumentos para a construção de dados concretos para a elaboração e execução de políticas curriculares, mediante uma movimentação que vem se intensificando e ampliando. Nesse processo, Bonamino e Sousa (2012) identificam três gerações, nas quais, os objetivos e as consequências acerca das avaliações vão se modificando.

A primeira geração enfatiza a avaliação voltada para o acompanhamento da evolução da qualidade da educação do país. Com caráter de diagnóstico, os dados não eram expostos de 
forma excessiva. As autoras identificam nessa geração, a primeira versão do Sistema Nacional de Avaliação da Educação Básica (SAEB), assim denominado a partir de 1991 e formalmente criado em 1994. Esse sistema, desde a sua criação, é compreendido como um mecanismo apropriado para diagnosticar e monitorar a educação básica nas diferentes regiões geográficas dos Estados Brasileiros.

Conforme Bonamino e Sousa (2012), paralelamente ao SAEB, a fim de intensificar o rastreamento da educação básica, os estados e municípios passaram a adotar sistemas próprios de avaliação, o que tornaram mais tarde e, progressivamente, em subsídios de políticas de responsabilização e no desdobramento de outras duas gerações de avaliações.

A segunda geração das avaliações em larga escala começa a apresentar consequências negativas, tendo em vista a ampla divulgação dos resultados, para que esses pudessem ser apropriados pela escola, pelos pais e pela sociedade. Pretendia-se por meio desse mecanismo de responsabilização impulsionar os pais e a comunidade a pressionarem a escola em prol de mobilizações de sua equipe em direção à melhoria do desempenho dos/as estudantes (BONAMINO; SOUSA, 2012).

Bonamino e Sousa (2012) identificam nessa geração a criação da Prova Brasil em 2005, que permite associar a perspectiva de diagnóstico à responsabilização. Sua criação se deu com a justificativa de que o SAEB possuía limites em retratar especificidades de municípios e escolas e em suscitar gestores/as públicos/as dos estados e municípios na elaboração de políticas direcionadas à melhoria do ensino. Dessa maneira, a Prova Brasil tornou-se base para as decisões dos governantes quanto ao direcionamento de recursos, bem como para o estabelecimento de metas e a implantação de ações pedagógicas e administrativas.

A terceira geração de avaliação em larga escala é pautada na política de responsabilização, contemplando sanções ou recompensas desinentes dos resultados dos/as alunos/as e das escolas, o que impacta amplamente no currículo escolar, tendo em vista que a preocupação em alcançar melhores resultados por parte das gestões é intensificada, levando-as a realizarem avaliações padronizadas e em períodos curtos. Vinculados a esses mecanismos, são implantados currículos uniformizados e voltados para o alcance de resultados (BONAMINO; SOUSA, 2012).

Por meio dessas estratégias, as avaliações em larga escala vêm sendo desenhadas pelo 
sistema educacional brasileiro. Como um instrumento de poder sobre as escolas, passaram a definir o currículo (CÁRIA; OLIVEIRA, 2015), logo, a determinar o quê, como e para quê ensinar, condição que cria uma logicidade, a qual submete todo o sistema educacional a mudanças, exigindo, sobretudo, deslocamentos no papel da escola.

Assim sendo, as avaliações em larga escala possuem o poder de estabelecer e de direcionar o trabalho pedagógico, induzindo a construção e o cumprimento de metas pelas escolas, bem como a bonificação salarial atreladas aos resultados, o acompanhamento de gestores/as, entre outras medidas (LOUZADA; MARQUES, 2015).

Por essa lógica, as avaliações em larga escala e o currículo se vinculam, de forma em que o segundo torna-se dependente das primeiras, e a escola, em suas diversas formas de organização, gestão e princípios, é afetada, pois se trata de uma relação articulada mediante uma concepção classificatória e excludente de avaliação, agregada a uma visão estreita e padronizada do currículo, que reduz o trabalho pedagógico a programas de preparação para testes, priorizando algumas áreas do conhecimento, a exemplo de português e matemática, e negando outras. De acordo com Louzada e Marques (2015, p.717), “o currículo, nessa concepção, passaria a ser uma espécie de manual para professores, indicando a organização do trabalho com o conhecimento. Um eixo condutor do trabalho docente em relação ao conhecimento escolar".

Esse alinhamento da escola à avaliação do rendimento constitui um interessante nicho do mercado na sociedade capitalista contemporânea, instalando um atraente mercado competitivo de produtos educacionais, que promete o alcance de melhores posições no ranking da intitulada qualidade da educação (SAUL, 2015). Nessa direção, "a prática das avaliações tem levado à redução do currículo aos conteúdos que são cobrados nas avaliações e, os alunos, por sua vez, são submetidos cada vez mais às práticas maçantes dos testes e ranqueamentos, além de pressões psicológicas pela transferência de responsabilização" (CÁRIA; OLIVEIRA, 2015, p.25).

A causa dessa condição é explicada por Freitas (2014). Para este autor, as elites historicamente sonegaram a dimensão do conhecimento às camadas populares, de modo que, para o empresariado, ainda eram confortáveis o analfabetismo e a baixa qualidade da educação. Contudo, as redes produtivas e do consumo demandaram mais conhecimento, pressionando-o a responder as seguintes questões: 
[...] como liberar um pouco mais de conhecimento para as camadas populares sem abrir mão do controle ideológico da escola, sem correr o risco de eventualmente abrir espaço para as teorias pedagógicas mais progressistas, comprometidas com as transformações da escola para além da versão tecnicista e escolanovista. Como, em um quadro de escassez de mão de obra barata, incorporar cada vez mais as camadas populares na escola básica, submetendoa à preparação para o mercado de trabalho? (FREITAS, 2014, p.1089).

Conforme o autor anteriormente citado, esse cenário é caracterizado pela necessidade de qualificação e, ao mesmo tempo, de controle ideológico, que move os reformadores a disputarem a educação e a criarem mecanismos de responsabilização da escola pelos resultados negativos. Nesse sentido, para Freitas (2014), o empresariado aceita a equiparação entre pobreza e baixa aprendizagem, entretanto, defende a tese liberal de que cabe à escola compensar as desigualdades, garantindo acesso ao conhecimento, mas em uma condição caracterizada como básica.

Nessa direção, assinala ainda Freitas (2014) que as reformas do currículo são direcionadas à adaptação do ensino aos princípios do mercado. Contudo, são defendidas e divulgadas como forma de inserção das camadas populares à "boa cultura" e como oportunidade de progresso, tirando o foco das raízes das desigualdades. A meritocracia ganha força nessa política, responsabilizando os/as estudantes pelos seus resultados, com o pretexto de que o diferencial está no esforço de cada um.

Acerca dessa condição, Zanotto e Sandri (2018) enfatizam que, as avaliações em larga escala apresentam-se como uma chave para a inserção do mercado capitalista à educação, uma vez que, por intermédio delas, é possível inserir no sistema educacional elementos que fazem parte do capitalismo: ranqueamento, competição e responsabilização.

Sob esse quadro, todo o sistema educacional é pressionado e convencido a buscar melhores classificações em avaliações nacionais e internacionais. Conforme Santos e Pereira (2016), isso se constitui em uma condição fecunda para o avanço do mercado na educação, que investe intensamente em prestações de serviços, vendas de material didático, cursos para professores/as e gestores/as, os quais têm como base seus pressupostos ideológicos. Por intermédio disso, vêm ocorrendo as parcerias público-privadas (que geralmente transferem recursos públicos para o setor privado) e as privatizações passam a ser as soluções para os problemas educacionais. 
Santos e Pereira (2016) abordam também que os padrões comuns ${ }^{4}$ são importantes para a formação de mão de obra e para o fortalecimento do mercado. Daí, os investimentos do setor privado em prestação de serviços e em ampliação de mecanismos de padronização do ensino se tornam promissores para a adequação e aceitação dos/as estudantes à doutrina neoliberal. Nesse sentido, a educação pública assume papel estratégico para o projeto neoliberal, sendo rentável aos negócios e fundamental para a reestruturação social respaldada pela ideologia mercadológica.

Por essa via, são diversas as mobilizações direcionadas para a padronização da educação, e, logicamente, em defesa de uma base nacional comum que, de acordo com Santos e Pereira (2016), é apoiada em função da perspectiva de melhoria dos resultados nos exames nacionais e internacionais. Por esse mesmo motivo, a Base Nacional Comum Curricular (BNCC), da Educação Infantil e do Ensino Fundamental de 2017 e do Ensino Médio homologada em 2018, é pauta de muitas críticas.

Para Zanotto e Sandri (2018), a BNCC revela-se um forte apelo mercadológico, que rompe com a autonomia pedagógica e valida a estandardização do currículo, ajustando-o aos indicadores cobrados nas avaliações em larga escala. Com esse entendimento, Dourado e Siqueira (2019) explicam que esta política pode ser considerada um tipo de reforma em que o currículo e o conhecimento são como objetos de regulação social. Para esses autores, a pedagogia das competências, que fundamenta a base, sustenta o modelo empresarial de responsabilização individual dos sujeitos em relação aos processos de aprendizagem e apropriação do conhecimento.

Desse modo, compreendemos que, embora a BNCC não esgote as possibilidades do que ocorre e é produzido nas escolas (MACEDO, 2018), trata-se de uma proposição prescritiva obrigatória que pode atuar de forma determinante na organização curricular das instituições. Assim sendo, em diálogo com Macedo (2018), alertamos que políticas como a base não trazem resultados de mais aprendizagem e justiça social, tendo em vista a sua intenção de regulação dos sujeitos.

\footnotetext{
${ }^{4}$ Vincula-se à lógica do domínio dos conhecimentos denominados universais, que estão intrinsecamente associados ao saber requerido pelo mercado e o saber acumulado pela burguesia (NEIRA; NUNES, 2009).
} 
Esse entendimento nos remete à Saul (2015), que defende uma educação freiriana ${ }^{5}$, sublinhando que a educação alicerçada no controle do currículo possui um propósito de domesticação dos sujeitos, na qual os/as educandos/as são passivos em relação ao conhecimento, que são a eles/as depositados como em uma ação "bancária", desarticulados de propósitos críticos voltados para a realidade. A autora acrescenta que:

A opção pela educação domesticadora acaba sendo o carro-chefe que puxa e condiciona a organização curricular, a seleção do conhecimento, os materiais didáticos, os chamados métodos de ensino, o sistema disciplinar, a relação com as famílias, a formação de professores e os processos de avaliação formais e informais, no interior da escola (SAUL, 2015, p.1304).

Com esse posicionamento, a autora vê tal condição como um movimento político ideológico que reduz o currículo e submete a escola às demandas da economia, regulando-a e limitando-a à busca de resultados das aprendizagens dos/as alunos/as nos exames. Em prol da produtividade, as redes de ensino e escolas legitimam a uniformização do currículo e naturalizam a inserção de empresas na educação pública, que, por meio de seus serviços, definem os projetos educacionais e os seus objetivos.

Dessa maneira, o ensino institucional, em vez de se preocupar com a aprendizagem dos/as alunos/as, passa a criar foco no desempenho em classificações numéricas, desconectando a docência de suas especificidades como profissão, no que diz respeito à demanda reflexiva e intelectual e criando barreiras que dificultam uma formação direcionada à leitura crítica e ativa dos/as educandos/as a respeito da sua realidade (LOUZADA; MARQUES, 2015).

Problematizando esse quadro, Cária e Oliveira (2015) alertam que, embora as escolas estejam reestruturando o currículo com o objetivo de atender às demandas das avaliações de larga escala, os resultados não têm demonstrado muito sucesso.

O empenho e dedicação de muitos professores e gestores em escolas carentes de periferias, muitas vezes, não têm sido suficientes para elevar a nota do IDEB, que continua baixa, pois a escola não tem o poder de superar diversos fatores sociais e culturais que interferem diretamente ou indiretamente no trabalho

\footnotetext{
${ }^{5}$ Trata-se de uma educação desenvolvida com base nos pensamentos do educador e filósofo Paulo Freire (19211997). O pensamento freiriano propõe uma educação escolar que respeite e reconheça as condições socioculturais dos/as alunos/as, instigando-lhes o senso crítico em relação à sociedade.
}

Periódico Horizontes - USF - Itatiba, SP - Brasil - e021063 
pedagógico da escola, inclusive em políticas de gestão dos governos municipal e estadual. Assim, não são poucos os casos em que as escolas da periferia continuam abandonadas à própria sorte, o que traz uma expectativa frágil aos profissionais da escola, aos pais e aos alunos (CÁRIA; OLIVEIRA, 2015, p.34).

O fato é que as avaliações em larga escala junto a um currículo unificado tendem a reforçar práticas avaliativas tradicionais e a pressionar os/as professores/as a ensinar todos os conteúdos presentes no currículo em um período pré-determinado, o que pode comprometer a aprendizagem dos/as alunos/as, uma vez que desconsidera a flexibilidade curricular necessária para atender às especificidades e ritmos diferenciados de aprendizagens (SOUSA; ARCAS, 2010).

Entendemos, portanto, que as avaliações em larga escala, ao negarem questões do contexto escolar vinculadas ao processo de ensino e de aprendizado, podem bloquear possibilidades emancipadoras ou tornarem-se um mecanismo de intensificação das desigualdades educacionais e sociais, condição que representa uma barreira para a democratização da educação brasileira e para o reconhecimento de grupos sociais e culturais específicos historicamente negados no currículo escolar.

\section{A diversidade cultural no contexto da centralidade das avaliações em larga escala}

A centralização das avaliações em larga escala e a sua associação ao mercado têm provocado mudanças no currículo escolar e, consequentemente, deslocamentos no papel da escola. Tais processos estão associados a um projeto específico de sociedade e à manutenção de determinada ordem social, cujos princípios geram tensões, conflitos e contradições em relação à função da escola.

Assim, se por um lado existe um discurso que incentiva e exige a adoção de um currículo com ênfase na pluralidade cultural e no questionamento das diferenças, visando a atender às peculiaridades dos/as estudantes, por outro, as escolas e os sistemas de ensino são forçados a adotar padrões e a buscar resultados estatísticos em conformidade com as demandas do mercado.

Esse quadro revela que o currículo escolar é um espaço de relações de poder, não podendo ser mais visto com a mesma inocência de antes, como um elemento neutro e 
desinteressado de conhecimentos. Trata-se de um instrumento que transmite visões particulares da sociedade, forjando, assim, identidades (SILVA, 2011).

A respeito dessa condição, é importante dialogar com Michael Apple, por intermédio de Silva (2011), que questiona: "Qual conhecimento - de quem - é privilegiado no currículo? Quais grupos se beneficiam e quais grupos são prejudicados pela forma como o currículo está organizado?" (p.49).

Segundo Freitas (2014), a escola sempre foi um espaço de disputas ideológicas, e, atualmente, as avaliações externas, tendo sua função ampliada, vêm se tornando um instrumento de disputa, bem como um elemento indutivo da padronização do currículo e do ensino. Essa condição, conforme Libâneo (2014 apud FREITAS, 2014) fortaleceu o alinhamento da escola a concepções didáticas julgadas superadas, isto é, tradicionais, tecnicistas.

Dessa maneira, as visões alternativas e críticas do currículo vão ficando cada vez mais sufocadas (FREITAS, 2014). Embora a padronização sustente-se em um discurso que sinaliza o direito de aprendizado a todos/as os/as discentes, as salas de aulas são formadas por alunos/as de múltiplas características, dificuldades e potencialidades, cujas diferenças não são consideradas (CÁRIA; OLIVEIRA, 2015). Ao desconsiderarem o contexto escolar, as articulações em torno das avaliações em larga escala acentuam as desigualdades entre as crianças e os processos de ensino/aprendizagem, bem como entre os/as docentes e instituições (DOURADO; SIQUEIRA, 2019).

Diante dessa condição, com base em Saul (2015), entendemos que cabe colocar em xeque a lógica da qualidade da educação atribuída à suposição e às expectativas em relação ao aumento dos índices de avaliação de rendimento escolar. Essa autora explicita que é preciso questionar o sentido das escolas para alunos/as que vivem em diversos contextos, submetidos às injustiças sociais, à discriminação, à exclusão e à violência, pois, por trás do discurso que se sustenta na necessidade de melhoria da qualidade da educação, está um projeto político que instaura padrões comprometedores de práticas equitativas e emancipatórias.

Com essa visão, Voss (2021) afirma que as políticas das avaliações em larga escala produzem efeitos perversos nas formas de acesso à cultura escolar, pois as formas como são calculadas as taxas e os índices não são suficientes para avaliar elementos específicos de cada contexto regional e local, que englobam as diferentes formas de aprendizagem, os interesses e as necessidades dos 
sujeitos envolvidos na escolarização, a diversidade cultural, a inclusão, a autonomia docente e da escola no processo de construção dos projetos políticos pedagógicos das escolas.

Em decorrência desse processo, os saberes e as culturas dos/as alunos/as raramente são reconhecidos e centralizados no currículo. As diferenças são vistas por meio de uma perspectiva individualizante, a qual vincula as adversidades das ações educativas a problemas pessoais dos/as alunos/as e, não, como um desafio de uma responsabilidade do sistema educacional (NEIRA; NUNES, 2009).

Essa situação é validada e estimulada a partir de situações citadas por Cerdeira, Almeida e Costa (2014) em relação as avaliações em larga escala e seus reflexos na escola, como: o foco no treino e nos exames e, não, no processo ensino-aprendizagem, a perda de aulas em função do excesso de testes realizados pelas escolas, o investimento de forma especial aos/às alunos/as com maior chance de elevar o desempenho da escola e o incentivo para que aqueles/as com baixo desempenho faltem às provas.

Macedo (2017), ao questionar a BNCC e sua proposição padronizadora e mercadológica, chama atenção para o potencial de exclusões validado pelo documento, pois desconsidera a realidade social e cultural brasileira e atinge grupos que timidamente vinham ocupando seus espaços. Nessa direção, no lugar de questões como a luta pela efetividade da lei 11.645/08 - que regulamenta a obrigatoriedade do Ensino da História e da Cultura Afro e Afro-brasileira e Indígena no currículo do Ensino Fundamental e do Ensino Médio de instituições públicas e privadas -, da pedagogia crítica, do reconhecimento dos/as estudantes do campo, de comunidades remanescentes quilombolas e populares, são validadas a normatização, o controle e a homogeneização, os quais naturalizam as desigualdades. A respeito desse cenário, Oliveira (2018) ressalta que:

A pluralidade do Brasil, ao contrário do caminho escolhido pelo governo ao insistir com a BNCC, exige pluralidade de possibilidades, de oferta de trajeto e de garantias de condições para que o processo ensino-aprendizagem ocorra. Para origens diferentes, necessidades diferentes, características sociais, culturais e econômicas diferentes, é preciso oferecer trajetórias diferentes! Tratar igualmente os desiguais é aprofundar a desigualdade! É inferiorizar alguns perante os outros. Reconhecer a necessidade de oferecer possibilidades DIVERSAS/PLURAIS de proposta e experiência curricular a alunos diferentes/desiguais é necessário para promover a equalização social e a 
redução das desigualdades. [...] Quando escolhemos o que entra nos currículos, escolhemos o que sai e esta decisão é política, favorece a alguns e prejudica outros. No caso brasileiro, vem sendo tomada em prejuízo das questões sociais, da formação crítica, da cidadania, do direito que se diz estar defendendo (OLIVEIRA, 2018, p.57).

Candau (2016) nos oferece reflexões valiosas para refutarmos a padronização do currículo e os mecanismos de exclusão do processo educacional. Consentimos com a autora quando sinaliza que a escola precisa ser reinventada, apontando a necessidade de um currículo intercultural crítico, um currículo voltado para o combate de todas as práticas que classificam e criam muros entre os escolares e grupos sociais e culturais, como as avaliações de rendimento, que punem os/as estudantes e desconsideram suas realidades. Com essa proposição, Candau (2016) ressalta que:

Não acreditamos na padronização, em currículos únicos e engessados e perspectivas que reduzem o direito à educação a resultados uniformes. Acreditamos no potencial dos educadores para construir propostas educativas coletivas e plurais. É tempo de inovar, atrever-se a realizar experiências pedagógicas a partir de paradigmas educacionais 'outros', mobilizar as comunidades educativas na construção de projetos político-pedagógicos relevantes para cada contexto ( $p .807)$.

O posicionamento da autora demonstra que a forma pela qual as avaliações em larga escala vêm sendo compreendidas e realizadas na educação brasileira as tornam uma estratégia desumana de exclusão, uma vez que vem sendo compreendida por uma perspectiva de base unificadora e homogeneizadora. Em diálogo com Candau (2016), Freitas (2012) ressalta que a lógica da política que vem alicerçando as avaliações em larga escala tem como elemento central a responsabilização, assim descarta a igualdade de condições e converte as diferenças sociais e culturais em diferenças de desempenho.

Assistimos um processo de intensificação da negação das diferenças, o qual permite que a educação brasileira continue sendo privilégio de grupos dominantes. Considerando os movimentos históricos do Brasil, caracterizados por exploração, desigualdades e pela concentração de poder, e que o desempenho cognitivo do/a aluno/a envolve aspectos econômicos, sociais e culturais, fica evidente quais sujeitos e grupos são as principais vítimas dessa condição. Além disso, com esse panorama, há uma tendência para a negligência de 
algumas conquistas de grupos historicamente silenciados no currículo, bem como o rompimento do trabalho pedagógico direcionado à formação crítica e ativa dos/as educandos/as, favorecendo a continuidade, a intensificação e a ampliação de práticas estereotipadas, preconceituosas e pejorativas no interior da escola e fora dela, consequentemente, a rejeição e a negligência da diversidade cultural.

Diante disso, com base em Ivo e Hypolito (2017), acreditamos que a busca pela melhoria da qualidade da educação escolar tem que considerar as desigualdades e singularidades dos diferentes contextos, pois caminhos iguais para cenários diversos fazem com que as metas propostas não sejam atingidas por todas as escolas e por todos/as os/as estudantes.

Nessa direção, urgem-se debates críticos referentes às políticas educacionais, no sentido de que estas possam ser construídas por uma concepção ampla de conhecimento, de formação e de currículos, bem como vinculadas às culturas e às múltiplas condições dos/as estudantes, porque uma educação comprometida com a produção e a disseminação do conhecimento reivindica a garantia de projetos formativos críticos, emancipatórios e contextualizados, logicamente, estratégias de avaliação capazes de diagnosticar, acompanhar e analisar o processo de ensino e de aprendizagem (DOURADO; SIQUEIRA, 2019).

É imprescindível combater a lógica segregacionista que atravessa a organização do currículo escolar. Assim sendo, ao defendermos uma educação intercultural crítica, acreditamos que o enfrentamento dessa condição requer mudanças epistemológicas, políticas e culturais da educação brasileira e da sociedade. Com essa perspectiva, coadunamos com Gomes (2020), no sentido de que seja necessário lutar contra os movimentos políticos fomentadores de projetos mercadológicos, universalistas e excludentes que vêm sendo potencializados nos últimos anos pela direita e extrema direita. Conforme a autora, é indispensável o combate desses movimentos, o que requer mudanças nas configurações de forças no Congresso Nacional, nas Assembleias Legislativas e nas Câmaras Municipais, buscando eleger candidatos/as de pensamentos e proposições equânimes.

\section{Considerações Finais}

Este ensaio propôs uma reflexão quanto as avalições em larga escala e suas implicações 
para o currículo escolar e a diversidade cultural. Através da escrita, buscamos chamar a atenção quanto às mudanças do currículo, por meio da centralização dessas avaliações, e, também, quanto aos mecanismos excludentes do ensino diante da intensificação dos processos de padronização, bem como das prioridades elegidas pela escola, a fim de alcançar melhores resultados nos exames e de adequar às demandas do mercado.

Desse modo, discutimos a respeito da lógica classificatória, seletiva, controladora e burguesa que configura as avaliações em larga escala, a qual se revela paradoxal e antidemocrática diante da diversidade presente na sala de aula, da pluralidade social e cultural do país, tornando-se uma barreira para o reconhecimento de grupos negados (populações negras, populações do campo e de comunidades remanescentes quilombolas, indígenas, entre outros) no currículo escolar.

Diante dessas condições, intensifica-se no campo educacional o processo de disputas entre os setores que buscam, através de currículos únicos, a adequação da escola e do ensino aos princípios do mercado e os que, incansavelmente, lutam por uma escola e uma sociedade mais equitativa. A busca por melhores resultados no desempenho dos/as estudantes vem enfraquecendo as lutas concernentes à educação enquanto um direito social de todos/as e fragilizando as conquistas de sujeitos historicamente excluídos.

A favor de uma educação intercultural crítica, emancipatória e equitativa, na qual as especificidades dos/as estudantes e a diversidade cultural sejam elegidas como prioridades e como fatores indispensáveis para a melhoria da qualidade da educação, defendemos avaliações que possibilitem diagnóstico, acompanhamento e análise do processo de ensino e de aprendizagem. Assim, refutamos a lógica mercadológica que avança na sociedade e acreditamos que é preciso lutar contra as políticas mercadológicas de direita e extrema direita que se ampliam na sociedade e no sistema educacional brasileiro.

Portanto, a fim de somar esforços, sugerimos o aprofundamento, a ampliação e a divulgação de estudos referentes às avaliações em larga escala e as suas implicações no currículo escolar, no sentido de mobilizar o sistema educacional como um todo, de colocar em xeque os mecanismos segregacionistas que vêm sendo naturalizados e fomentados por meio das avaliações em larga escala e de ressignificar a sua função na educação escolar brasileira. 


\section{Referências}

BONAMINO, A.; SOUSA, S. Z.; Três gerações de avaliação da educação básica no Brasil: interfaces com o currículo da/na escola. Educação e Pesquisa, São Paulo, v.38, n.2, p.373-388, abr./jun.2012. DOI: https://doi.org/10.1590/S1517-97022012005000006. Acesso em: 11 nov. 2020.

CANDAU, V. M. F. Cotidiano escolar e práticas interculturais. Cadernos de Pesquisa. v.46, n.16. p.802-820, jul./set. 2016. DOI: http://dx.doi.org/10.1590/198053143455. Acesso em: 13 nov. 2020.

CÁRIA, N. P.; OLIVEIRA, S. M. S. S. Avaliação em larga escala e a gestão da qualidade da educação. Revista de Ciências Humanas - Educação, v.16, n.26. p.22-40, jul. 2015. Disponível em: http://revistas.fw.uri.br/index.php/revistadech/article/viewFile/1477/1853 Acesso em: 03 dez. 2020.

CERDEIRA, D. G. S.; ALMEIDA, A. B.; COSTA, M. Indicadores e avaliação educacional: percepções e reações a políticas de responsabilização. Est. Aval. Educ., São Paulo, v.25, n.57, p.198-225, jan./abr. 2014. DOI: https://doi.org/10.18222/eae255720142845. Acesso em: 08 jul. 2020.

DOURADO, F. L.; SIQUEIRA, R. M. A arte do disfarce: BNCC como gestão e regulação do currículo. RBPAE, v.35, n.2, p.291-306, mai./ago. 2019. DOI:

https://doi.org/10.21573/vol35n22019.95407. Acesso em: 12 jan. 2021.

FREITAS, L. C. Os reformadores empresariais da educação: da desmoralização do magistério à destruição do sistema público de educação. Educação e Sociedade, Campinas, v.33, n.119, p.379-404, abr./jun.2012. Disponível em: http://www.cedes.unicamp.br. Acesso em: 12 mar. 2021.

FREITAS, L. C. Responsabilização, meritocracia e privatização: como conseguiremos escapar ao neotecnicismo? In: PINO, I. R.; ZAN, D. D. P. (orgs.). Plano nacional da educação (PNE): questões desafiadoras e embates emblemáticos. Brasília: Inep, 2013, p.47-84.

FREITAS, L. C. Os reformadores empresariais da educação e a disputa pelo controle do processo pedagógico na escola. Educ. Soc., Campinas, v.35, n. 129, p.1085 - 1114, out./dez., 2014. DOI: https://doi.org/10.1590/ES0101-73302014143817. Acesso em: 03 fev. 2020.

GOMES, N. L. Diversidade e currículo. In: BEAUCHAMP, J.; PAGEL, S. D.; NASCIMENTO, A. R. Indagações sobre currículo: diversidade e currículo. Brasília: Ministério da Educação. Secretaria de Educação Básica, 2007, p.17-47.

GOMES, N. L. A questão racial e o novo coronavírus no Brasil. In: HEUSER, C.; HABERMANN, W. (org.). Trabalho e justiça social, São Paulo: Friedrich Ebert Stiftung (FES), p. 2-7, 2020. 
HOFFMAN, J. Avaliar para promover: as setas do caminho. Porto Alegre: Mediação, 2001.

HYPOLITO, A. M. Políticas curriculares, estado e regulação. Educ. Soc., Campinas, v.31, n.113, p.1337-1354, out./dez. 2010. DOI: http://dx.doi.org/10.1590/S0101-73302010000400015. Acesso em: 05 mar. 2021.

IVO, A. A.; HYPOLITO, A. M. Sistemas de avaliação em larga escala e repercussões em diferentes contextos escolares: limites da padronização gerencialista. RBPAE, v.33, n.3, p.791-809, set./dez. 2017. DOI: https://doi.org/10.21573/vol33n32017.79308. Acesso em: 18 nov. 2020.

LOUZADA, V.; MARQUES, R. Políticas de regulação para a educação no Brasil: interfaces entre currículo, avaliação e formação docente. Revista e-Curriculum, São Paulo, v.13, n. 4, p.711-732, out./dez. 2015. Disponível em: http://revistas.pucsp.br/index.php/curriculum. Acesso em: 10 fev. 2021.

MACEDO, E. As demandas conservadoras do movimento escola sem partido e a base nacional curricular comum. Revista Educ. Soc., Campinas, v.38, n.139, p.507-524, abr./jun. 2017. DOI: https://doi.org/10.1590/ES0101-73302017177445 Acesso em: 05 mar. 2021.

MACEDO, E. "A base é a base": e o currículo o que é? In: AGUIAR, M. A. S.; DOURADO, L. F. (orgs.). A BNCC na contramão do PNE 2014-2024: avaliação e perspectivas. [livro eletrônico]. Recife: ANPAE, 2018, p.28-33.

NEIRA, M. G.; NUNES, M. L. F. Educação, currículo e cultura. São Paulo: Phorte, 2009.

OLIVEIRA, I. B. Políticas curriculares no contexto do golpe de 2016: debates atuais, embates e resistências. In: AGUIAR, M. A.; DOURADO, L. F. (orgs.). A BNCC na contramão do PNE 20142024: avaliação e perspectivas. [livro eletrônico]. Recife: ANPAE, 2018, p.55-59.

SAUL, A. M. Na contramão da lógica do controle em contextos de avaliação: por uma educação democrática e emancipatória. Educ. Pesqui., v.41, n. especial, p.1299-1311, 2015. DOI: https://doi.org/10.1590/S1517-9702201508143035. Acesso em: 15 dez. 2020.

SANTOS, L. L. C. P.; PEREIRA, J. E. D. Tentativas de padronização do currículo e da formação de professores no Brasil. Cad. Cedes, Campinas, v.36, n.100, p.281-300, set./dez., 2016. DOI: https://doi.org/10.1590/CC0101-32622016171703. Acesso em: 14 dez. 2020.

SILVA, T. T. Documentos de identidade: uma introdução às teorias do currículo. 3. ed. Belo Horizonte, Autêntica, 2011.

SOUSA, S. Z.; ARCAS, P. H. Implicações da avaliação em larga escala no currículo: revelações de escolas estaduais de São Paulo. Educação: Teoria e Prática, v.20, n.35, p.181-199, jul./dez.

2010. Disponível em:

https://www.periodicos.rc.biblioteca.unesp.br/index.php/educacao/article/view/4091. Acesso em: 04 jan. 2021. 
VOSS, D. M. S. Trabalho e saúde docente no jogo biopolítico das reformas educacionais. Revista Educação e Cultura Contemporânea, PPGE/UNESA, Rio de Janeiro v.18, n.52, p.358-377, 2021. DOI: http://dx.doi.org/10.5935/2238-1279.20210017. Acesso em: 02 abr.2021.

ZANOTTO, M; SANDRI, S. Avaliação em larga escala e BNCC: estratégias para o gerencialismo na educação. Revista Temas \& Matizes, Cascavel, v.12, n.23, p.127-143, jul./dez. 2018. Disponível em: https://e-revista.unioeste.br/index.php/temasematizes/article/view/21409. Acesso em: 08 dez. 2020.

Recebido em abril 2021.

Aprovado em setembro 2021. 